\title{
PREÇO DE TRANSFERÊNCIA E SEUS IMPACTOS CONTÁBEIS E FISCAIS DENTRO DE UMA EMPRESA DE FILTROS AUTOMOBILÍSTICOS NA IMPORTAÇÃO E EXPORTAÇÃO DE MERCADORIAS
}

\author{
TRANSFER PRICE AND ITS ACCOUNTING AND TAX IMPACTS WITHIN A \\ AUTOMOTIVE FIL TERS COMPANY IN IMPORTS AND EXPORTS OF GOODS
}

\author{
JOSIANE GATTIS CORREA GIACOMELLI \\ Mestra em Saúde e Meio Ambiente pela Universidade da Região de \\ Joinville. Professora do Centro Universitário Leonardo da Vinci e da \\ Faculdade Cenecista de Joinville. Endereço: Avenida Getúlio Vargas, \\ 1266 / Anita Garibaldi / Joinville/SC / Brasil. \\ E-mail: giacomellijosiane@gmail.com
}

HELOISA DE AGUIAR

Graduada em Ciências Contábeis pela Sociedade Educacional de Santa Catarina (SOCIESC). Endereço: Gothard Kaesemodel, 833 / Anita Garibaldi / Joinville/SC / Brasil.

E-mail: heloisaa@joinville.unimedsc.com.br

\section{RESUMO}

A legislação brasileira exige lançamentos contábeis específicos, quando o assunto é Preço de Transferência. Essas regras existentes foram criadas para evitar que as empresas brasileiras com subsidiárias no exterior possam utilizar a estratégia de evasão de divisas, já que sem ordenamento jurídico adequado os preços poderiam ser subavaliados para que não houvesse o devido pagamento dos tributos, na transferência de produtos ao exterior. O objetivo deste estudo consiste em verificar os impactos contábeis e fiscais no uso do preço de transferência na importação e exportação de mercadorias, para uma empresa do ramo automobilístico. Para tanto, utilizou-se a pesquisa aplicada, por meio da coleta de dados documentais e entrevista não estruturada. Considerando as penalidades legais quando a legislação não é aplicada corretamente, apresentou-se o seguinte problema de pesquisa: Quais os impactos contábeis e fiscais, quando aplicados as formas de cálculo adequadas ao preço de transferência? Os resultados obtidos para o cálculo da importação para o produto P603 mostraram que o método PRL Revenda, por obter o menor ajuste comparado ao método PIC no ano de 2014, foi o mais adequado a ser utilizado no cálculo do preço de transferência. No momento da exportação o método CAP foi o mais adequado contábil e fiscalmente, para os produtos F175F13 e R161F042, por ser o único método possível para calcular o preço de transferência para a empresa estudada. Como conclusão da pesquisa, verificou-se que a utilização dos métodos recomendados pela legislação fiscal vigente no Brasil poderiam contribuir para a qualidade da informação contábil e, ao mesmo tempo, resultariam num aumento da base de cálculo dos tributos incidentes sobre a receita.

Palavras-chave: Preço de transferência. Contabilidade gerencial. Ajustes fiscais. Companhias subsidiárias. Importação. Exportação. 


\begin{abstract}
Brazilian law require specific accounting entries, when the subject is Transfer Price. These existing rules were created to prevent Brazilian companies with foreign subsidiaries from using the foreign currency drain strategy, since without appropriate system of laws; prices could be undervalued so that there would be no due payment of taxes in the transfer of products abroad. The objective of this study is to verify the accounting and tax impacts on the use of the transfer price in the import and export of goods, for an automotive company. For this, the applied research was used, through the collection of documentary data and unstructured interview. Considering the legal penalties when the law is not applied properly, the following research problem was presented: What are the accounting and tax impacts, when the calculation methods appropriate to the transfer price are applied? The results obtained for the calculation of the import for the product P603 showed that the PRL Resale method, to obtain the lowest adjustment compared to the PIC method in the year 2014, was the most appropriate to be used in the calculation of the transfer price. At the time of export, the CAP method was the most appropriate accounting and tax for the products F175F13 and R161F042, since it was the only possible method to calculate the transfer price for the company studied. As a conclusion of the research, it was verified that the use of the methods recommended by the current Brazilian tax law could contribute to the quality of the accounting information and, at the same time, would result in an increase in the calculation basis of the taxes on income.
\end{abstract}

Keywords: Transfer price. Management accounting. Tax adjustments. Subsidiary companies. Import. Export.

\title{
1 INTRODUÇÃO
}

O Comércio internacional tem como característica fazer com que os países intercambiem os bens e serviços em um fluxo cada vez mais ágil. Com o forte crescimento de empresas multinacionais no Brasil, o preço de transferência, também conhecido internacionalmente como transfer price, tem sido utilizado para controlar operações comerciais e financeiras realizadas com empresas ligadas e domiciliadas no exterior.

Muitas empresas têm operações ao redor do mundo e frequentemente administram as subsidiárias em uma base geográfica. Em geral, essas subsidiárias efetuam transações de compra e venda de mercadorias ou serviços. As autoridades fiscais desempenham um papel de reguladores dos valores transferidos nessa transação, de forma coercitiva e também de regulação, para evitar a evasão de divisas (Newton \& Steevens, 2013).

A legislação brasileira exige lançamentos contábeis específicos, quando o assunto é preço de transferência. Existem penalidades legais quando a legislação não é aplicada ou quando é aplicada incorretamente, o que pode inviabilizar os resultados operacionais.

Tendo em vista a necessidade de evitar perdas de receitas fiscais, o preço de transferência é um instrumento importante que tem como função primordial evitar o aumento indevido dos custos de empresas com operações entre partes vinculadas ou quando uma das partes reside em paraíso fiscal. Com a introdução da Lei n. 9.430 (1996), existe a tendência de estabelecer critérios de controle tributário e ajuste dos preços de transferência praticados.

Estudos empíricos, como o apresentado por Chen \& Chen (2014), discutem o preço de transferência em consonância com a teoria da agência e sugerem uma padronização para o uso de taxa de impostos e valores adequados a serem utilizados no preço de transferência, como forma de influenciar o sistema de mediação de desempenho e também da transferência de autonomia de preços.

Dessa forma, o objetivo do presente artigo é analisar as formas de cálculo de preço de transferência aplicáveis na exportação e importação de mercadorias em uma indústria multinacional de filtros automobilísticos. Para delimitação da pesquisa foi estabelecido o seguinte problema: Quais os impactos contábeis e fiscais, quando aplicados as formas de cálculo adequadas ao preço de transferência?

Com o intuito de alcançar o objetivo central, foram classificados os objetivos específicos, como analisar as regras brasileiras de preços de transferência aplicáveis nas importações e exportações de mercadorias, calcular as formas mais apropriadas aos produtos 
propostos no estudo, verificar os impactos contábeis e, por fim, analisar os efeitos fiscais pela utilização dos métodos do preço de transferência.

A pesquisa aplicada configurou o delineamento deste estudo, que se utilizou de dados e entrevista não estruturada para efetuar a análise e verificar os impactos do preço de transferência nos produtos estudados.

Sendo assim, este artigo traz os conceitos teóricos sobre o uso do preço de transferência, a metodologia adotada, os resultados encontrados e a conclusão da aplicação do estudo na prática, como forma de corroborar o objetivo central desta pesquisa.

\section{PREÇO DE TRANSFERÊNCIA}

Preço de transferência é o valor de compra ou de venda de bens, serviços ou direitos, comercializados entre unidades organizacionais de uma mesma empresa que sejam localizadas em países distintos. Esses valores podem acarretar acréscimo para mais ou para menos nos valores de mercado.

Para Higuchi (2015), com a regulamentação da Lei n. 9.430 (1996), foi dado um grande passo na legislação brasileira para diminuir o superfaturamento nas importações e o subfaturamento nas exportações. Na maioria das vezes não se trata de elisões lícitas, mas de fraudes até grosseiras. Com o advento da lei que traz a definição de preços de transferências, o risco de as empresas desonestas serem autuadas se tornou mais elevado.

Estão obrigadas às regras de preços de transferência todas as pessoas físicas ou jurídicas residentes no Brasil que praticarem operações com pessoas físicas ou jurídicas residentes no exterior, consideradas vinculadas ou, também, ainda que não vinculadas, que residam em país que não tribute a renda ou que tribute à alíquota inferior a vinte por cento (Andrade, 2011).

Para controle de preço de transferência vinculada será considerada somente a pessoa física ou jurídica residente ou domiciliada no exterior, que possui uma companhia situada no Brasil e que realiza transações entre elas. Nesse sentido, faz-se apropriada a definição do art. 23 da Lei n. 9.430/96, que considera pessoa jurídica domiciliada no Brasil aquela cuja matriz ou filial esteja formalmente constituídas em território nacional.

Para Schoueri (1999, p.111), preço de transferência é "o valor cobrado por uma empresa na venda ou transferência de bens, serviços ou propriedade intangível, a empresa a ela relacionada". Com os métodos da importação e exportação, determina-se que o preço parâmetro deve ser consistente para cada bem, serviço ou direito, para todo o ano-calendário. Sendo que, a empresa pode optar por um dos métodos para cada mercadoria ou matéria-prima diferente, ou seja, utilizar métodos diferentes para mercadorias diferentes, desde que não mude de método no ano-calendário. Com isso, poderá ter excesso de custo em um bem e não ter em outro.

Nas operações de importação e exportação de mercadorias com empresas coligadas calcula-se o preço de transferência conforme métodos contidos na Tabela 1.

Tabela 1

Métodos de importação e exportação

\begin{tabular}{c|c}
\hline Importação & Exportação \\
\hline PIC & PVEx \\
\hline PRL Produção & PVV \\
\hline PRL Revenda & PVA \\
\hline CPL & CAP \\
\hline PCl & PECEX \\
\hline
\end{tabular}

Nota. Fonte: Adaptado da Lei n. 9.430, 27 de dezembro de 1996 (1996). Dispõe sobre a legislação federal, as contribuições para a seguridade social, o processo administrativo de consulta e dá outras providências. Recuperado de http://www.planalto.gov.br/ccivil_03/leis/L9430.htm 
Preço praticado é o preço médio efetivamente realizado nas importações ou exportações do período em questão, envolvendo a pessoa vinculada ou com origem. Já o preço parâmetro é o preço obtido por meio de um dos métodos estipulados na legislação de preços de transferência. O excesso de custo pago na importação ou a receita de venda menor recebida na exportação, envolvendo a pessoa vinculada ou o paraíso fiscal, é considerado lucro e portando base para tributação do CSLL e IR, se tornando é o ajuste ou exposição fiscal.

Segundo a Instrução Normativa n. 1.312, art. 3, de 28 de dezembro de 2012, os custos, despesas e encargos relativos aos bens, serviços e direitos, são os constantes dos documentos de importação ou de aquisição, nas operações efetuadas com pessoa vinculada. São dedutíveis na determinação do lucro real e da base de cálculo da contribuição social somente até o valor que não exceda o preço determinado por um dos métodos previstos em lei (Kimi Shiraishi, Gonzales, \& Fernandes dos Santos, 2015).

Schäfer, Petri, Gasparetto \& Mattos, em 2015, publicaram uma pesquisa bibliométrica sobre a literatura internacional focada no preço de transferência e demonstraram que a maioria dos autores pesquisados procura trabalhar os apectos gerenciais do preço de transferência e que há ainda um vasto caminho a ser explorado nesse tema, já que os aspectos contábeis e tributários são menos explorados.

Já Morch, Castro, Castro e Cogan (2008) e Checoli (2013) estudaram o preço de transferência em títulos financeiros para bancos, evidenciando a necessidade de estudos apurados sobre o tema. Cripe, Harmon e West (2015) aplicaram um estudo contábil/fiscal em uma empresa com matriz na Itália e filial no Estados Unidos, com o objetivo de demonstrar a influência do correto uso do preço de transferência nas demonstrações financeiras. Concluíram que há uma influência significativa da aplicação do preço de transferência de forma correta na informação contábil.

Quando se trata de ativos intangíveis, o preço de transferência possui sua significância, pois se trata de um item também suportado para essa categoria de ativos. A pesquisa de Franklin e Mayers (2016) apresenta um histórico dos tribunais internacionais sobre o preço de transferência em relação ao mercado americano. Subsidia-se na necessidade de regulamentação e de criação de armas legais que considerem a utilização desta ferramenta.

Kumar e Sosnoski (2011) propuseram em seu estudo a prevensão de problemas relacionados ao preço de transferência para empresas de pequeno e médio porte. Avaliaram a necessidade de clareza em relação às questões fiscais e redução da exposição dessas empresas à dupla tributação.

O preço de transferência pode alterar a informação contábil, fiscal e gerencial. $O$ trabalho realizado por Araujo (2013) verificou o efeito gerencial, considerando as formas de cálculo do preço de transferência e seu impacto na margem de contribuição de uma empresa brasileira, vinculada a uma empresa chinesa.

\subsection{Preço de transferência na importação de mercadorias}

$\mathrm{Na}$ importação de mercadorias, os preços a serem utilizados como preço parâmetro serão comparados com os constantes documentos de aquisição, observando se o preço praticado na aquisição da empresa vinculada é superior àquele utilizado como preço parâmetro. São adicionados ao lucro real os valores resultantes do excesso de custo, computado nos resultados da empresa, decorrente da diferença entre os preços comparados. Dessa forma, pode-se dizer ainda que se o preço for inferior, nenhum ajuste com efeito tributário poderá ser efetuado.

De acordo com o art. 45, I, II da Lei n. 10.637 (2002), nos casos de apuração de excesso de custo de aquisição de bens, serviços e direitos importados de empresas vinculadas e que sejam considerados indedutíveis na determinação do lucro real e da base de cálculo da contribuição social sobre o lucro líquido, a pessoa jurídica deverá ajustar o excesso de custo, determinado por um dos métodos previstos na legislação, no encerramento do período de apuração, contabilmente, por meio de lançamento a débito de conta de resultados acumulados e a crédito de conta do ativo em que foi contabilizada a aquisição dos bens, direitos ou serviços. Esses lançamentos devem permanecer ali registrados ao final do período de apuração, ou e conta própria de custo ou de despesa do período de apuração, que registre o 
valor dos bens, serviços ou direitos, no caso desses ativos já terem sido baixados da conta de ativo que tenha registrado a sua aquisição.

O método PIC, ou método dos preços independentes comparados, está disposto no Art. 18, I, da Lei n. 9.430 (1996). Foi definido como a média aritmética ponderada dos preços de bens, serviços ou direitos, idênticos ou similares, apurados no mercado brasileiro ou de outros países, em operações de compra e venda, empreendidas pela própria interessada ou por terceiros, em condições de pagamentos semelhantes.

Significa então que o método compara o preço cobrado por propriedade ou serviços em uma transação controlada com aquele cobrado por propriedade ou serviço em uma transação comparável independente. Se houver diferenças deverão ser feitos ajustes precisos para eliminar o impacto devido.

O método do preço de revenda menos lucro ou PRL tem sua normatização de acordo com o art. 18, II, da Lei n. 9.430 (1996), e é definido como a média aritmética ponderada dos preços de venda no país, dos bens, direitos ou serviços importados, em condições de pagamentos semelhantes e calculados.

Esse método será utilizado na hipótese de bens, serviços ou direitos importados aplicados à produção e a revenda. Nessa hipótese, o preço parâmetro dos bens, serviços ou direitos importados será apurado excluindo-se o valor agregado no País e a margem de lucro de sessenta por cento até 2012 e a partir de 2013 com a margem de lucro de quarenta por cento, trinta por cento ou vinte por cento, de acordo com o setor da atividade econômica.

Se a empresa importar o mesmo bem para ser revendido e aplicado na produção de um ou mais produtos, ou na hipótese de o bem importado ser submetido a diferentes processos produtivos no Brasil, o preço parâmetro final será a média ponderada dos valores encontrados mediante a aplicação do Método PRL.

Em 2013, houve alteração na legislação brasileira, fazendo passar o percentual de sessenta por cento para quarenta por cento, trinta por cento e vinte por cento, dependendo de cada setor industrial (Higuchi, 2015).

O método do custo de produção mais lucro, conhecido como CPL, é definido como o custo médio ponderado de produção de bens, serviços ou direitos, idênticos ou similares dos impostos e taxas cobrados na exportação no país onde tiverem sido originariamente produzidos e de margem de lucro de vinte por cento, calculada sobre o custo apurado.

$\mathrm{Na}$ determinação do custo do bem, serviço ou direito, adquirido pela empresa no Brasil, os custos referidos, incorridos pela unidade produtora no exterior, serão considerados proporcionalmente às quantidades destinadas à empresa no Brasil.

No caso de utilização de produto similar, para aferição do preço, o custo de produção deverá ser ajustado em função das diferenças entre o bem, serviço ou direito adquirido e o que estiver sendo utilizado como parâmetro. A margem de lucro de vinte por cento, será aplicada sobre os custos apurados antes da incidência dos impostos e taxas, cobrados no país de origem, sobre o valor dos bens, serviços e direitos adquiridos pela empresa no Brasil.

Para Andrade (2012), na apuração de preço por esse método serão considerados exclusivamente os custos incorridos na produção do bem, serviço ou direito, excluídos quaisquer outros, ainda que se refiram à margem de lucro de distribuidor atacadista.

Ainda, segundo o mesmo autor, da mesma forma, pode-se dizer que os custos de produção deverão ser demonstrados discriminadamente, por componente, valores e respectivos fornecedores. Poderão ser utilizados dados da própria unidade fornecedora ou de unidades produtoras de outras empresas, localizadas no país de origem do bem, serviço ou direito. Para efeito de determinação do preço por esse método, poderão ser computados como integrantes do custo: (a) o custo de aquisição das matérias-primas, dos produtos intermediários e dos materiais de embalagem utilizados na produção do bem, serviço ou direito; (b) o custo de quaisquer outros bens, serviços ou direitos aplicados ou consumidos na produção; (c) o custo do pessoal, aplicado na produção, inclusive de supervisão direta, manutenção e guarda das instalações de produção e os respectivos encargos sociais incorridos, exigidos ou admitidos pela legislação do país de origem; (d) os custos de locação, manutenção e reparo e os encargos de depreciação, amortização ou exaustão dos bens, serviços ou direitos aplicados na produção; (e) os valores das quebras e perdas razoáveis, ocorridas no processo produtivo, admitidas pela legislação fiscal do país de origem do bem, serviço ou direito. 
$\mathrm{O} \mathrm{PCl}$ (método do preço sob cotação na importação), conforme o art. 18-A da Lei $\mathrm{n}$. 9.430 (1996), é definido como os valores médios diários da cotação de bens ou direitos sujeitos a preços públicos em bolsa de mercadorias e futuros internacionalmente reconhecidos. A lei obriga o uso desse método quando o produto atender cumulativamente ao requisito de produto commodity.

Considerando a relevância do tema, estudos anteriormente publicados, como os de Pedó, Muller e Cortimiglia (2011); Padhi e Bal (2015), elaboraram um trabalho com o intuito de identificar os impactos decorrentes das limitações legais quanto ao preço de transferência no Brasil e no mundo, nas importações de mercadorias, cuja proposta comparou, inclusive, as normas já revogadas e que perpetuam com processos judiciais, devido à grande quantidade de situações concernentes ao assunto.

\subsection{Preço de transferência na exportação de mercadorias}

Conforme o art. 19 da Lei n. 9.430 (1996), as receitas auferidas nas operações efetuadas com pessoa vinculada ficam sujeitas a arbitramento quando o preço médio de venda dos bens, serviços ou direitos relacionados à exportação, efetuada durante o período de apuração da base de cálculo do imposto de renda, for inferior a noventa por cento do preço médio praticado na venda dos mesmos bens, serviços ou direitos, no mercado brasileiro, durante o mesmo período e em condições de pagamentos semelhantes.

De acordo com o art. $6^{\circ}$ da Instrução Normativa n. 1.312/12, a determinação do preço médio praticado na exportação e o preço médio de comparação serão obtidos pela multiplicação dos preços pelas quantidades relativas a cada operação e os resultados apurados serão somados e divididos pela quantidade total, determinando-se, assim, o preço médio ponderado.

É importante destacar que o contribuinte deve verificar se a exportação será efetuada com pessoas vinculadas, com pessoa física ou jurídica, que for residente ou domiciliada em país que não tribute a renda ou que tribute a renda inferior a vinte por cento.

Isso significa que se o contribuinte se enquadrar nas hipóteses citadas, fica obrigado a efetuar a comparação para determinar o preço médio das vendas dos bens, serviços e direitos nas exportações efetuadas no período de apuração da base de cálculo do imposto. Se os preços de vendas nas exportações forem inferiores a noventa por cento, as receitas das vendas serão desconsideradas e os valores deverão ser arbitrados utilizando um dos cinco métodos previstos no $\S 3^{\circ}$ do art. 19 da Lei n. 9.430 (1996).

Na exportação, os métodos utilizados, apresentados no Tabela 1, são definidos como:

a) Método do preço de venda nas exportações - PVEx: De acordo com o art. 19, $\S 3^{\circ}$, I da Lei n. 9.430 (1996), é definido como a média aritmética dos preços de venda de bens similares nas exportações efetuadas pela própria empresa, para outros clientes ou por outra exportadora nacional de bens, serviços ou direitos, durante o período de apuração da base de cálculo do Imposto de Renda e em condições semelhantes de pagamentos.

b) Método do preço de venda por atacado no país de destino, diminuído do lucro - PVA: No art. 19, $\S 3^{\circ}$, II, da Lei n. 9.430 (1996), é definido como a média aritmética dos preços de venda de bens, idênticos ou similares, praticados no mercado atacadista do país de destino, em condições de pagamento semelhantes, diminuídos dos tributos incluídos no preço, cobrados no referido país, e de margem de lucro de quinze por cento sobre o preço de venda no atacado.

c) Método do preço de venda a varejo no país de destino, diminuído do lucro PVV: De acordo com o art. 19, § $3^{\circ}$, III, da Lei n. 9.430 (1996), é definido como a média aritmética dos preços de venda de bens, idênticos ou similares, praticados no mercado varejista do país de destino, em condições de pagamento semelhantes, diminuídos dos tributos incluídos no preço cobrado no referido país, e de margem de lucro de trinta por cento sobre o preço de venda no varejo.

d) Método do custo de aquisição ou de produção mais tributos e lucro - CAP: De 
acordo com o art. 19, $\S 3^{\circ}$, IV , da Lei n. 9.430 (1996), é definido como a média aritmética dos custos de aquisição ou de produção dos bens, serviços ou direitos exportados, acrescidos dos impostos e contribuições cobrados no Brasil e de margem de lucro de quinze por cento sobre a soma dos custos mais impostos e contribuições.

e) Método do preço sob cotação na exportação - PECEX: Conforme o art. 19-A da Lei n. 9.430 (1996), é definido como os valores médios diários da cotação de bens ou direitos sujeitos a preços públicos em bolsas de mercados e futuros internacionalmente reconhecidas.

Dessa forma, uma empresa, sempre que transferir ou receber produtos de uma subsidiária no exterior deverá obedecer aos preceitos constantes na legislação, para o preço de transferência. Não pode, em qualquer hipótese, praticar o que melhor lhe couber.

\section{METODOLOGIA}

O presente estudo é uma análise do preço de transferência na importação e exportação de mercadorias em uma empresa de filtros automobilísticos sediada no Brasil. Sua matriz na Suíça. Teve-se como objetivo principal demonstrar os impactos da contabilização do ajuste nos resultados.

Empresa com filial brasileira inaugurada no ano de 1997 abriu caminhos para novas fábricas em outros países. Em tempos de mudanças e de ampliação no ramo automotivo, a empresa sempre ficou ciente do desenvolvimento do setor automobilístico que foi crescendo rapidamente. Com a preocupação do crescimento saudável, focado em perspectivas para o futuro, a referida empresa tende a diminuir o consumo de matéria-prima para futuramente facilitar o processo de descarte e reciclagem. Como produto principal no setor automobilístico, a empresa no Brasil fabrica peças completas para veículos de grandes montadoras. A filial brasileira presta atendimento ao cliente, entre montadoras e a todo o mercado brasileiro de peças de reposição. Pode, assim, desenvolver soluções e atender às necessidades dos clientes. Por motivos de sigilo profissional o nome da empresa foi ocultado, preservando-se apenas os resultados obtidos no estudo de caso.

Este trabalho classifica-se como pesquisa aplicada. Procura produzir conhecimentos para aplicação prática em relação a um determinado problema. Sua abordagem é qualitativa, já que se apropria de dados para elaboração e análises baseadas em legislação e coleta de dados, sem o uso de procedimentos estatísticos.

A coleta de dados envolveu os documentos contábeis quanto aos produtos estudados e entrevista não estruturada com o contador da empresa. A entrevista ocorreu em outubro de 2015 e a coleta de dados deu-se no período de agosto a outubro de 2015. Pela grande quantidade de produtos com a possiblidade de análise do preço de transferência, foram utilizados o F175F13 e o R161F042 para a exportação e o P603L para a importação, por serem produtos com um grande volume de exportação e importação de mercadorias. Os dados quanto a esses produtos surgiram por meio das notas fiscais de entrada/saída, relatórios internos e demonstrações contábeis referentes ao ano-calendário de 2014. Os cáculos foram conduzidos a verificar os procedimentos mais adequados no tratamento fiscal, de acordo com a legislação vigente no Brasil, e posteriormente os efeitos contábeis dessa alteração fiscal, na contabilidade da empresa.

\section{RESULTADOS ALCANÇADOS}

Por meio da análise dos dados coletados nesta pesquisa, observou-se a ausência de práticas, de acordo com a legislação vigente, de preços de transferência para os produtos estudados. Portanto, os resultados apurados estão baseados nos cálculos feitos, considerando a necessidade e a obrigação legal dessa prática.

Os médotos de cálculos foram divididos em duas etapas: produto importado, primeiramente e, em seguida, produtos exportados. 


\subsection{Cálculos dos métodos de importação}

Os dados encontrados para importação do produto, aqui denominado Filtro P603L, foram calculados, considerando os quatro métodos na importação de mercadorias, permitidos em legislação, para poder identificar o procedimento mais adequado para esse produto. Verificou-se, então, que esse produto é oriundo da empresa vinculada na Suíça e tem como finalidade sua revenda no mercado interno brasileiro. Os cáculos elaborados para cada método são apresentados abaixo, considerando a Tabela 2, com a simulação do primeiro cálculo, pelo método PIC.

Tabela 2

\section{Cálculo método PIC}

\begin{tabular}{l|l|l|l}
\multicolumn{1}{c|}{ P603L } & \multicolumn{1}{|c|}{ Condição } & \multicolumn{1}{c|}{ Média } & \multicolumn{1}{c}{ Observações } \\
\hline Aquisições Vinculadas & 370 peças por $\mathrm{R} \$ 29.514,90$ & $\mathrm{R} \$ 79,77$ & Preço Praticado \\
\hline \multirow{2}{*}{ Outras Aquisições } & 18.741 peças por $\mathrm{R} \$ 927.828,75$ & $\mathrm{R} \$ 49,51$ & Preço Parâmetro \\
\hline \multirow{2}{*}{} & Com margem 5\% & $\mathrm{R} \$ 51,98$ & $(\mathrm{R} \$ 49,51+5 \%)$ \\
\cline { 2 - 4 } & Diferença & $\mathrm{R} \$ 30,26$ & $(\mathrm{R} \$ 79,77-\mathrm{R} \$ 49,51)$ \\
\cline { 2 - 4 } & Quant. Total Importada & 370 & \\
\cline { 2 - 4 } & Total do Ajuste & $\mathrm{R} \$ 11.196,20$ & $(370 \times \mathrm{R} \$ 30,26)$ \\
\hline
\end{tabular}

Nota. Fonte: As autoras.

Verificou-se que o preço parâmetro está inferior ao preço praticado. Nesse método, acrescenta-se $5 \%$ (cinco por cento) ao preço parâmetro para verificar a possibilidade de seu preço estar dentro da margem de divergência. Apurado, mesmo com o acréscimo da margem de divergência, o preço parâmetro ainda está inferior ao preço praticado. Então, deve-se apurar a diferença entre o preço praticado com o preço parâmetro, para multiplicar pela quantidade importada, e, assim, chegar ao valor do ajuste.

Se a empesa utilizasse esse método estaria pagando por um produto importado de sua vinculada um custo mais elevado, ou seja, estará deixando divisas no país de origem.

Para o método PRL Revenda foi analisado o mesmo filtro P603L, conforme Tabela 3.

Tabela 3

Cálculo Método PRL Revenda

\begin{tabular}{l|l|l|l}
\hline \multicolumn{1}{c|}{ P603L } & \multicolumn{1}{|c|}{ Condição } & Média & \multicolumn{1}{c}{ Observações } \\
\hline Aquisições Vinculadas & 370 peças por $\mathrm{R} \$ 29.514,90$ & $\mathrm{R} \$ 79,77$ & Preço Praticado \\
\hline Vendas & 364 peças por $\mathrm{R} \$ 43.686,83$ & $\mathrm{R} \$ 120,02$ & \\
\hline & $-20 \%$ Lucro & $\mathrm{R} \$ 96,02$ & Preço Parâmetro (R\$ 120,02-20\%) \\
\cline { 2 - 4 } & Com margem 5\% & $\mathrm{R} \$ 100,82$ & $(\mathrm{R} \$ 96,02+5 \%)$ \\
\hline
\end{tabular}

Nota. Fonte: As autoras.

Para o cálculo do método de Preço de Revenda menos o Lucro - PRL, analisou-se o preço praticado, que é a média dos preços de aquisições na importação de vinculada com o preço parâmetro, calculado pela média dos preços de mercadorias das vendas desse produto importado, deduzindo vinte por cento de lucro e calculando a margem de divergência de cinco por cento.

Dessa forma, o preço parâmetro é superior ao preço praticado. Isso significa que a empresa obtém um lucro de vinte por cento ou mais acima do valor que foi adquirido pela vinculada, ou seja, a empresa consegue vender seu produto com o lucro estipulado em lei e não tem a necessidade de efetuar nenhum ajuste em seus resultados. 
Tabela 4

Demonstração das opções para cálculo

\begin{tabular}{l|l}
\multicolumn{1}{c}{ Métodos } & \multicolumn{1}{c}{ Opções para cálculo } \\
\hline PIC & Calculado - Ajuste de $\mathrm{R} \$ 11.196,20$ \\
\hline PRL Produção & Não há como calcular, produto P603L Elem Filtrar é produto de revenda \\
\hline PRL Revenda & Calculado - Não há ajuste \\
\hline CPL & Não há como calcular, vinculada não disponibiliza o custo discriminado. \\
\hline PCl & Não há como calcular, método para produtos cotados em bolsa (commodity) \\
\hline
\end{tabular}

Nota. Fonte: As autoras.

A empresa sediada no Brasil importa o filtro P603L somente para revender, ou seja, não utiliza qualquer processo de industrialização nesse filtro. Sendo assim, o cálculo do método do PRL Produção não se aplica para esse produto.

A vinculada não fornece discriminadamente os valores dos custos incorridos na produção do bem, como registros constantes dos livros contábeis, faturas comerciais de aquisição das matérias-primas e outros bens utilizados na produção, planilhas de rateio do custo de mão de obra, cópias das folhas de pagamentos, gastos com manutenção e reparos dos equipamentos aplicados a produção, demonstrativos dos percentuais e dos encargos de depreciação, amortização ou exaustão utilizados. Ainda, não apresenta a cópia da declaração do imposto sobre a renda entregue pelo fisco de seu País. Dessa forma, não é possível efetuar o cálculo do método do CPL.

O produto é um filtro automobilístico. Ele não se enquadra na lista de commodities previstas na IN RFB n 1.395, de 13 de setembro de 2013. Então nesse caso, o cálculo do método do $\mathrm{PCl}$ não se aplica.

O objetivo principal do preço de transferência na importação é fazer com que as empresas efetuem compras nacionais para gerar riquezas para o Brasil.

\subsection{Cálculos de métodos de exportação}

De acordo com as diretrizes da Lei n. 9.430 (1996), foram elaboradas as análises dos cinco métodos de exportação referentes aos filtros F175F13 e R161F042, para identificar o melhor método a ser utilizado para o cálculo de ajuste em seus resultados.

Com base nos dados coletados, calculou-se o método CAP para o filtro F175F13, conforme Tabela 5.

\section{Tabela 5}

Cálculo método CAP filtro F175F13 Filtrar

\begin{tabular}{l|l|l|l}
\hline \multicolumn{1}{c|}{ F175F13 } & \multicolumn{1}{c|}{ Condições } & \multicolumn{1}{c}{ Média } & \multicolumn{1}{c}{ Observações } \\
\hline \multirow{2}{*}{ Exportações Vinculadas } & $\begin{array}{l}\text { 20.616 peças por } \mathrm{R} \$ \\
8.359 .765,11\end{array}$ & $\mathrm{R} \$ 405,50$ & Preço Praticado \\
\hline CPV/CMV & $\mathrm{R} \$ 7.398 .670,08$ & $\mathrm{R} \$ 358,88$ & \\
\hline \multirow{2}{*}{$+15 \%$ Lucro } & $\mathrm{R} \$ 412,71$ & Preço Parâmetro (R\$ 358,88+15\%) \\
\cline { 2 - 4 } & Sem Margem $-5 \%$ & $\mathrm{R} \$ 392,07$ & $(\mathrm{R} \$ 412,71-5 \%)$ \\
\hline
\end{tabular}

Nota. Fonte: As autoras.

Pela análise dos cálculos, a empresa possui um custo elevado referente ao preço de venda. Conforme o art. 19, $\S 3^{\circ}$, IV, da Lei n. 9.430 (1996), acrescentou-se quinze por cento ao custo da mercadoria vendida à vinculada para verificar se houve o lucro exigido em lei. Nesse caso, com o acréscimo de quinze por cento, o preço praticado está inferior ao preço parâmetro. Isso significa que a empresa não está cobrando o lucro mínimo exigido em lei. Então diminuiuse a margem de divergência de cinco por cento, para, assim, haver a possibilidade do produto 
ficar dentro da margem e não haver o ajuste.

De acordo com os dados levantados na empresa, calculou-se o método CAP para o filtro R161F042, conforme Tabela 6.

\section{Tabela 6}

Cálculo método CAP filtro R161F042

\begin{tabular}{|c|c|c|c|}
\hline R161F042 & Condições & Média & Observações \\
\hline $\begin{array}{l}\text { Exportaçõs } \\
\text { Vinculadas }\end{array}$ & $\begin{array}{l}1.200 \text { peças por } \\
\mathrm{R} \$ 98.664,00\end{array}$ & $\mathrm{R} \$ 82,22$ & Preço Praticado \\
\hline \multirow[t]{6}{*}{ CPV/CMV } & $\mathrm{R} \$ 61.848,00$ & $\mathrm{R} \$ 81,54$ & \\
\hline & $+15 \%$ Lucro & $\mathrm{R} \$ 93,77$ & Preço Parâmetro (R\$ 81,54 + 15\%) \\
\hline & Sem Margem - 5\% & $\mathrm{R} \$ 89,08$ & $(\mathrm{R} \$ 93,77-5 \%)$ \\
\hline & Diferença & $\mathrm{R} \$ 11,55$ & $(\mathrm{R} \$ 93,77-\mathrm{R} \$ 82,22)$ \\
\hline & Quant. Total Export. & 1.200 & \\
\hline & Total Ajuste & $\mathrm{R} \$ 13.860,00$ & $(1.200 \times \mathrm{R} \$ 11,55)$ \\
\hline
\end{tabular}

Nota. Fonte: As autoras.

Em relação ao custo com o preço de venda, verificou-se que a empresa vendeu para sua vinculada com um lucro de menos de um por cento. Conforme a legislação do método CAP, a empresa deveria ter exportado para sua vinculada com um lucro mínimo de quinze por cento.

Mesmo calculando a margem de divergência para esse produto, haverá a necessidade de ajuste no resultado, pois o valor exportado não atingiu o mínimo estabelecido em lei. Dessa forma, apurou-se a diferença entre o preço praticado com o preço parâmetro para se multiplicar pela a quantidade total exportada do ano e se chegar ao ajuste total do produto.

A empresa estudada não tem como efetuar o cálculo do PVEx, tanto para o filtro F175F13 como para o R161F042, pois exporta somente para sua vinculada, o que impossibilita a comparação de preço praticado com o preço parâmetro de outras exportações de empresas independentes.

Conforme a Lei n. 9.430 (1996), para efetuar o cálculo do método PVV e PVA, há a obrigação de exportação para sua vinculada e essa revender para o varejo ou para o atacado. Assim, esses dois métodos não se aplicam neste estudo, uma vez que a vinculada compra do Brasil para utilização no processo de fabricação.

De acordo com o art. 19-A da Lei n. 9.430 (1996), o método PECEX somente é calculado para produtos cotados em bolsa (commodity). Esse método não se aplica para indústria de filtros automobilísticos.

\subsection{Ajuste}

A Escrituração Contábil Fiscal (ECF) do Imposto de Renda (IRPF) e da Contribuição Social sobre o Lucro Líquido (CSLL) veio para substituir a escrituração o Livro de Apuração do Lucro Real (Lalur), em relação a fatos ocorridos a partir de $1^{\circ}$ de janeiro de 2014.

Os ajustes do preço de transferência se tratados de acordo com a norma fiscal e ajustados na contabilidade da empresa trariam uma alteração em seus resultados, já que os valores para os produtos exportados seriam maiores, gerando uma receita de exportação mais alta do que as receitas atualmente praticadas. Em contrapartida, o produto importado geraria um custo adicional pelo método PIC e um custo menor na utilização do médoto PLR Revenda.

Os ajustes fiscais, se não adotados contabilmente, seriam somente discriminados na declaração anual da ECF, registro M300 - lançamentos da parte A do e-lalur, conforme Figura 1. 


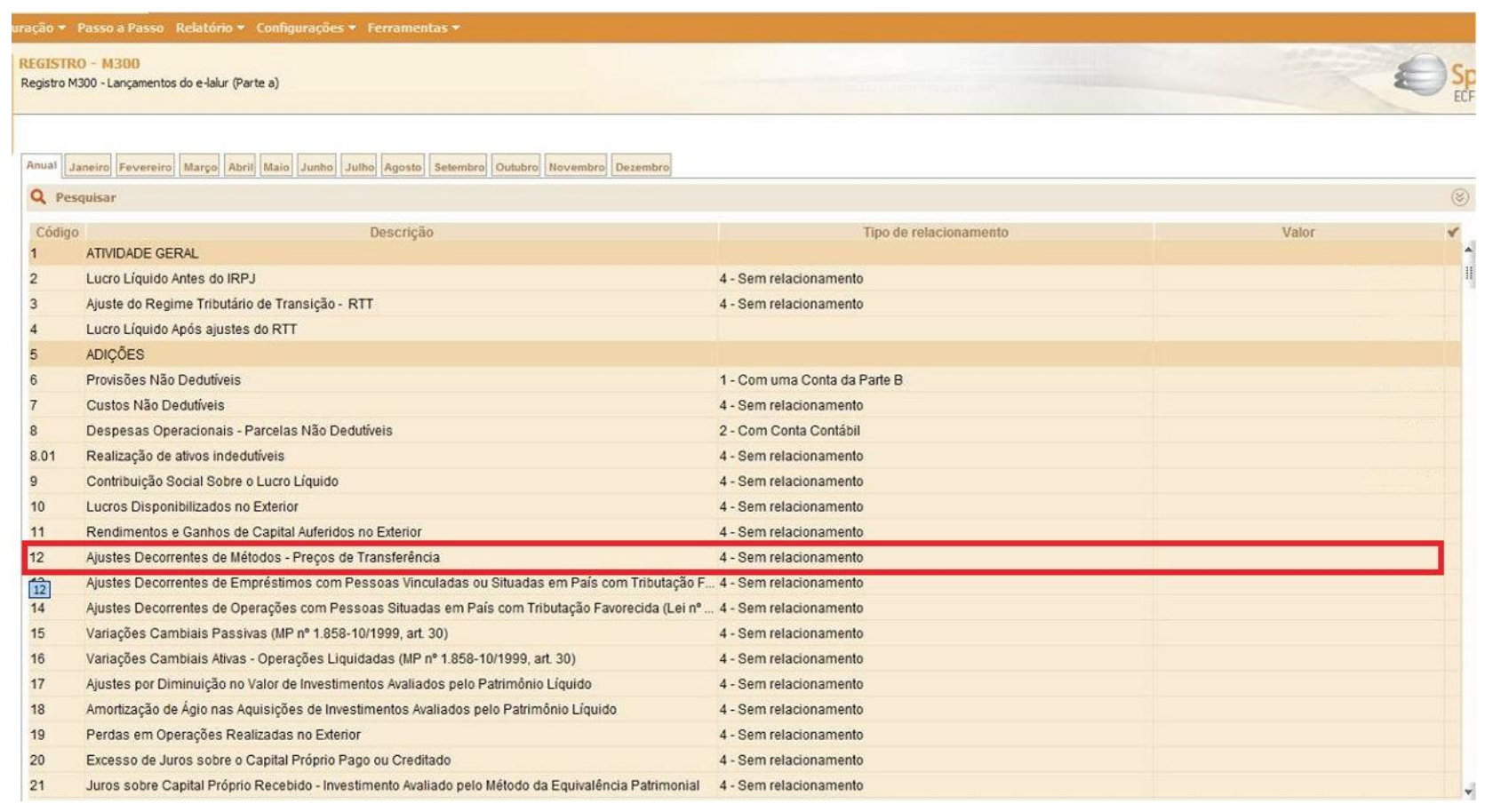

Figura 1. Declaração Sped ECF

Fonte: Sistema Sped ECF.

Percebe-se na Figura 1 que há um campo chamado Ajustes Decorrentes de Métodos Preço de Transferência, no ECF, justamente para contemplar situações relacionadas ao preço de transferência, devido a sua obrigatoriedade.

\subsection{Auto de infração}

A empresa, de acordo com a entrevista realizada com o coordenador contábil da instituição, utiliza o preço de transferência. Pelos cálculos e análises apresentados neste estudo, não há evidência dessa prática, como demonstrado anteriormente. Dessa forma, incorre no risco de fiscalização, já que não exerce o que é determinado em legislação. O preço de transferência não é somente um método para verificar preços de venda ou de compra. Por meio dele classificam-se os tributos que serão pagos pela empresa, como o IRPJ e a CSLL. A Receita Federal tem como obrigação fazer o lançamento do ofício que pode trazer consequências pesadas para a empresa, como a exclusão ou suspensão do CNPJ ou aplicação de multas.

De acordo com a Lei n. 11.488 (2007), os valores a serem pagos pela empresa, devido à multa do preço de transferência, trazem prejuízos altos e devem ser pagos primeiramente setenta e cinco por cento sobre a totalidade ou diferença entre os tributos pagos e os julgados devidos, o que é definido pelo agente do fisco, e, ainda, cinquenta por cento sobre o valor de pagamento mensal do imposto de renda do lucro líquido quando pessoa jurídica.

O fisco também poderá solicitar para fiscalizar os últimos cinco anos conforme a legislação o permite. Pode também autuar com multas se houver algum tipo de irregularidade nos cálculos do preço de transferência.

\section{CONCLUSÃO}

A Lei n. 9.430 (1996) dita regras para apuração do preço de transferência que vêm sendo cada vez mais exigidas para os contribuintes que fazem operações de importação e exportação com empresas relacionadas.

Este artigo foi elaborado com o objetivo de estudar o preço de transferência dentro de uma empresa de filtros automobilísticos, e seus impactos contábeis e fiscais, como Imposto de Renda (IRPJ) e Contribuição Social sobre o Lucro Líquido (CSLL) a legislação brasileira 
permite ao contribuinte a opção de escolha do método a ser utilizado, que possa trazer o menor ajuste. Com a complexidade associada aos preços de transferência é importante ser efetuado um planejamento tributário com o planejamento estratégico, que indicará o método considerado o melhor para os negócios da empresa. Se houver esse planejamento, ao identificar que ao produto está ocorrendo ajuste, a empresa tem a possibilidade de negociar com sua vinculada a transferência do lucro do referido produto para outro que não esteja dando ajuste.

A partir de todas as informações coletadas e analisadas de importação, foi verificado que apenas dois métodos, o PIC e o PRL Revenda, podem ser aplicados no produto estudado, nas importações. No método do PIC houve um ajuste no valor de R\$ 11.196,20 (onze mil, cento e noventa e seis reais e vinte centavos) e no método de PRL Revenda não houve ajuste, pois, o preço praticado esta inferior ao preço parâmetro. Conclui-se, pois, que o melhor método a ser utilizado para a importação referente ao filtro P603L é o método de PRL Revenda por não haver ajuste no ano de 2014.

Com os dados coletados e analisados para a exportação, foi concluído que apenas o método CAP poderá ser utilizado para o cálculo de preço de transferência nos dois produtos estudados F175F13 e R161F042. Para o filtro F175F13 não houve ajuste, uma vez que o valor está dentro da margem de divergência. Para o filtro R161F072 houve um ajuste no valor de R\$ $13.860,00$ (treze mil, oitocentos e sessenta reais), que será lançado no LALUR referente ao ano de 2014.

Por meio da simulação realizada, foi exemplificada a importância do preço de transferência dentro de uma empresa. Também se demonstrou que, diante das premissas apresentadas nos exemplos, haveria ajuste a realizar.

Conclui-se que o preço de transferência é nada mais que uma forma de evitar que empresas burlem o sistema aduaneiro, fazendo o processo correto e os ajustes conforme solicitado em lei. A empresa não terá danos futuros, como multas ou exclusão do cadastro nacional de pessoa jurídica, conforme mostrado nos estudos apresentados por Newton e Steeves (2013); Pedó, Muller e Cortimiglia (2011); Schäfer (2016).

Também por meio do presente estudo de caso, evidenciou-se, de uma forma mais clara, como pode ser aplicado o preço de transferência dentro de uma indústria de filtros automobilísticos, direcionado para um planejamento de seus gestores referente aos preços de compra e de venda para suas ligadas. Considerando as situações apresentadas, afirma-se que os objetivos propostos nesta pesquisa foram plenamente atendidos.

As limitações deste trabalho estão em falta de dados e acesso a documentos que pudessem calcular outros exercícios e produtos. Sugere-se para trabalhos futuros uma análise em produtos e seu impacto nos lucros da empresa a ser estudada, considerando principalmente o efeito desse lucro na distribuição a sócios e acionistas.

\section{REFERÊNCIAS}

Andrade, E. O., Filho (2011). Imposto de renda das empresas. São Paulo: Atlas.

Araujo, P. H. E. D. (2013). Preço de transferência: os efeitos fiscais e financeiros de produtos importados de uma empresa vinculada. Dissertação de Mestrado, Universidade Federal do Rio Grande do Sul, Porto Alegre, RS, Brasil.

Borges Morch, R., Souza Castro, G. D., Camargo Bicudo de Castro, V. D., \& Cogan, S. (2008). Preço de transferência de fundos: um estudo para o mercado financeiro. Revista contemporânea de contabilidade, 5(9).

Checoli, A. G. (2013). Preço de transferência de passivos sem vencimento de bancos comerciais: uma abordagem para aplicações automáticas (Doctoral dissertation).

Chen, C. X., Chen, S., Pan, F., \& Wang, Y. (2014). Determinants and Consequences of Transfer Pricing Autonomy: An Empirical Investigation. Journal of Management Accounting Research, 27(2), 225-259.

Cripe, B. M., Harmon, A., \& West, T. D. (2015). Lenzini Steel: The Impact of Transfer Pricing and Taxes on International Operations. Issues in Accounting Education, 31(4), 369-387. 
Franklin, M., \& Myers, J. K. (2016). An Analysis of Transfer Pricing Policy and Notable Transfer Pricing Court Rulings. Journal of Business and Accounting, 9(1), 73.

Higuchi, H. (2015). Imposto de renda das empresas. São Paulo: IR Publicações.

Instrução Normativa n. 1.312 de 28 de dezembro de 2012. (2012). Dispõe sobre os preços a serem praticados nas operações de compra e de venda de bens, serviços ou direitos efetuados por pessoa física ou jurídica residente ou domiciliada no Brasil, com pessoa física ou jurídica residente ou domiciliada no exterior, consideradas vinculadas. Recuperado http://sijut2.receita.fazenda.gov.br/sijut2consulta/link.action?\&visao=.Original\&idAto=3925 7.

Kimi Shiraishi, P., Gonzales, A., \& Fernandes dos Santos, R. (2015). Preços de transferênciaos impactos da nova metodologia de cálculo trazida pela Lei n. 12.715 de 2012. Enfoque: Reflexão Contábil, 34(3).

Kumar, S., \& Sosnoski, M. (2011). Decision framework for the analysis and selection of appropriate transfer pricing for a resilient global SME manufacturing operation-a business case. International Journal of Production Research, 49(18), 5431-5448.

Lei n. 10.637, de 30 de dezembro de 2002. (2002). Dispõe sobre a não-cumulatividade na cobrança da contribuição para os Programas de Integração Social (PIS) e de Formação do Patrimônio do Servidor Público (Pasep), nos casos que específica; sobre o pagamento e o parcelamento de débitos tributários federais, a compensação de créditos fiscais, a declaração de inaptidão de inscrições de pessoas jurídicas, a legislação aduaneira, e dá outras providências. Recuperado de http://www.planalto.gov.br/ccivil_03/leis/2002/l10637.htm

Lei n. 11.488, de 15 de junho de 2007. (2007). Cria o Regime Especial de Incentivos para o Desenvolvimento da Infra-Estrutura - REIDI; reduz para 24 (vinte e quatro) meses o prazo mínimo para utilização dos créditos da Contribuição para o PIS/Pasep e da Contribuição para o Financiamento da Seguridade Social - COFINS decorrentes da aquisição de edificações; amplia o prazo para pagamento de impostos e contribuições; altera a Medida Provisória n 2.158-35, de 24 de agosto de 2001, e as Leis nos 9.779, de 19 de janeiro de 1999, 8.212, de 24 de julho de 1991, 10.666, de 8 de maio de 2003, 10.637, de 30 de dezembro de 2002, 4.502, de 30 de novembro de 1964, 9.430, de 27 de dezembro de 1996, 10.426, de 24 de abril de 2002, 10.833, de 29 de dezembro de 2003, 10.892, de 13 de julho de 2004, 9.074, de 7 de julho de 1995, 9.427, de 26 de dezembro de 1996, 10.438, de 26 de abril de 2002, 10.848, de 15 de março de 2004, 10.865, de 30 de abril de 2004, 10.925, de 23 de julho de 2004, 11.196, de 21 de novembro de 2005; revoga dispositivos das Leis nos 4.502, de 30 de novembro de 1964, 9.430, de 27 de dezembro de 1996, e do Decreto-Lei no 1.593, de 21 de dezembro de 1977; e dá outras providências. Recuperado de http://www.planalto.gov.br/ccivil_03/_ato20072010/2007/lei/l11488.htm

Lei n. 9.430, 27 de dezembro de 1996 (1996). Dispõe sobre a legislação federal, as contribuições para a seguridade social, o processo administrativo de consulta e dá outras providências. Recuperado de http://www.planalto.gov.br/ccivil_03/leis/L9430.htm

Newton, L. W., \& Steeves, C. J. (2013). Preço de Transferência. In J. P. Catty. IFRS: Guia de Aplicação do Valor Justo. Bookman Editora.

Padhi, S., \& Bal, R. K. (2015). Transfer Pricing Regulations \& Litigation-A Critical Appraisal based on Tribunal Judgements. Vilakshan: The XIMB Journal Of Management, 12(1).

Pedó, M. G. B., Muller, C. J., \& Cortimiglia, M. N. (2011). Impactos tributários dos métodos de cálculo de preços de transferência em operações de importação. REAd: revista eletrônica de administração, 17(1), 268-295.

Schäfer, J. D. (2016). Fatores contingenciais que afetam a escolha do preço de transferência. 
Schäfer, J. D., Petri, S. M., Gasparetto, V., \& dos Santos Mattos, L. (2015). Preços de transferência: uma análise bibliométrica da literatura internacional. Apresentação, 10(3), 71-85.

Schoueri, L. E. (1999). Preços de transferência no direito tributário brasileiro. São Paulo: Dialética.

Souza, M. A., Cardoso, M. F., \& Machado, R. (2012). Análise de custos na cadeia de valor: estudo de caso em uma empresa multinacional do setor petrolífero. RIC-Revista de Informação Contábil, 5(4), 1-25. 